\title{
DECLARACIÓN DE ABANDONO. LA PROBLEMÁTICA JURÍDICA Y PSICOLÓGICA DE LOS MENORES DURANTE EL PROCEDIMIENTO DE INVESTIGACIÓN TUTELAR PERUANO
}

Rosa Alicia Ornteño Apaza

Resumen

Este artículo critica la falta de celeridad en los procesos de investigación previos a la declaración de abandono de menores de edad. Se plantea como solución que en el proceso se incluya no sólo una investigación jurídica exhaustiva, sino, también, una psicológica. Esto deviene de dos razones principales: En primer lugar, debido a la falta de comunicación continua entre las instituciones pertinentes, Juzgados especializados, RENIEC y el Ministerio Público. En segundo lugar, que no exista una auditoria psicológica en todo el proceso de investigación previo a la declaración de abandono para los menores de edad. Esto, en gran medida, ayudaría a evitar la revictimización del menor.

\section{Summary}

This article criticizes the lack of speed in the research process prior to the declaration of abandonment of children. It is proposed as a solution in the process includes not only a comprehensive legal research. but also a psychological one. This comes from two main reasons: First, due to lack of ongoing communication hetween relevant Institutions, Specialized Courts, REIVIEC and the Public Ministry. Second, that there isn 't a psychological audit throughout their search process prior to the declaration of abandonment for minors. This last subject, in large measure, helps us to prevent there victimization of children.

\section{Sommaire}

L'article critique le manque de célérité de Tenquéte préalable a la declaration d'abandon d 'enfants. La solution proposée est que le procés comprenne non seulement une enquéte juridique globale, mais aussi une enquéte de nature psychologique. Cela répond á deux raisons principales. d'une part, le manque de communication entre les institutions concernées, les tribunaux spécialisés, RENIEC et le Ministére Publique. D 'autre part. il n 'y a pas un audit psychologique pendant le processus d'enquéte avant la déclaration dábandon de mineurs. Ceci pourrait, en grande mesure, aider á éviter une nouvelle victimisation du mineur. 
Cuanto más estudiamos la

naturaleza humana con su capacidad para establecer relaciones individuales $y$ sociales, con tanta mayor

claridad llegamos a

comprender que somos dueños de un caudal de energía natural que, al no ser encausada y dirigida, se malgasta o da lugar a perturbaciones. Margareth A.

\section{INTRODUCCIÓN}

La familia y la sociedad son entidades que se complementan teniendo en cuenta la dinámica donde no solo ambas entidades logran el equilibrio necesario para un país, sino a su vez podrían destruirse, siendo la crisis de la sociedad el resultado de una familia que fracasa en el cumplimiento de su misión ya que ella es donde se inicia el proceso de desarrollo de un carácter y culmina con la conquista de una personalidad.

A falta de una familia, este rol es cumplido por instituciones con políticas adecuadas y especialistas que se encargan de mantener el equilibrio necesario en los niños que se encuentran en estado de abandono. Es decir, estaríamos hablando de una nueva dinámica; ya no el de la familia-sociedad, sino, el de Institución-Estado, donde dicho equilibrio va tratar de no verse dañado más de lo que ya está, al tener bajo su tutela gran porcentaje de menores.

Los menores en estado de abandono, durante el tiempo que dura una Investigación tutelar son albergados mediante el INAB1F en los Centros de Atención Residencial - CAR, dicho procedimiento tutelar tiene por plazos ya estipulados en nuestro actual código Niños y adolescentes. Código que cuenta con reglamentos y mecanismos idóneos para lograr cumplir con el interés superior del niño que tanto interesa al estado.

Pero, ¿qué sucede cuando esta investigación dura por la ya conocida carga procesal, más tiempo de lo debido? No estamos hablando de derechos de propiedad, ni derechos de marcas, o en todo caso, de sanciones penales cometidos por personas que están en espera de una sentencia judicial el cual definirá su estado legal.

Estamos hablando precisamente de personas que deberían tener prioridad en cuanto a la celeridad procesal tan deseada por todos los litigantes. Afortunadamente y lamentablemente, el estado es quien forma parte de todos los convenios que protegen los derechos del niño. Atreviéndome a decir " desafortunadamente", ya que el hecho de contar legislación "adecuada" hace que irremediablemente se quede en manos de los juzgados de familia por un tiempo extendido no solo al doble de tiempo sino durante años para que se puedan "cumplir" con todas las exigencias procesales antes de dictar un auto de abandono.

No obstante, siendo el eje de todo este intento de investigación, tener como base el interés superior del niño; el niño es declarado en abandono, cuando lamentablemente ya es casi un mayor de edad. 


\section{LA INVESTIGACION TUTELAR EN NUESTRA LEGISLACIÓN}

Si bien es cierto, la investigación tutelar es un tema ya regulado específicamente por la Ley del Código del Niño y adolescente, ésta fija parámetros donde todo el procedimiento se encuentra con plazos fijados muy lejanos a la realidad y al encontrarse con múltiples obstáculos para realizar las diligencias fijadas, trae como resultado el no tener posibilidades de cumplir sus principal objetivo: salvaguardar los derechos del menor en estado de abandono.

De la mano con este proceso, se encuentran los tratamientos psicológicos que siguen los menores, el cual, se inicia con un perfil psicológico iniciado por el equipo multidisciplinario del poder judicial y el que posteriormente se pasa a evaluar en los CAR del INAB1F a cargo del menor. Dichos tratamientos no logran sus objetivos a la falta de un sistema que permita trabajar en forma conjunta con los juzgados de familia tutelar y peor aún, a raíz de la dilatada espera, se dan situaciones donde la persona agrava su estabilidad psicológica llegando incluso al punto del abandono de los CAR por parte de los menores.

\section{1. / Cuánto dura realmente un procedimiento de investigación tutelar?}

Uno de los mayores problemas es la duración del proceso de investigación tutelar, y cómo una dinámica más fluida entre las instituciones a cargo de los menores y los juzgados de familia tutelar pueden contribuir a proteger el interés superior del niño. De igual forma, una posible solución la encontraríamos en un método de seguimiento a los menores más eficaz del actual, teniendo una nueva dinámica al alcance de los juzgados de familia por medio de auditorías o programas establecidos con intervalos de tiempo menos extensos fomentaría a que los procesos de investigación tutelar tengan un alcance real en el ámbito no solo jurídico, sino a los programas psicológicos aplicados, ambos, con seguimiento por parte del juzgado sin necesidad de requerirlos para tener cercanía a los avances alcanzados por dichos programas aplicados a los menores mientras dure la investigación y antes de declarar el estado de abandono. ${ }^{1}$

\subsection{INAB1F}

El programa Integral para el bienestar Familiar - INABIF es una Unidad Ejecutoria del Ministerio de la Mujer y Desarrollo Social MIMDES, especializada en la ejecución de Programas Sociales dirigidos a promover la protección integral de niños, niñas, adolescentes, jóvenes y adultos que se encuentran en situación de riesgo o abandono .

En el año 2008 el congreso de la República mediante Ley 29247 derogó al decreto Supremo 005-2007-mindes, que creó la Dirección General de Protección Social sobre la base de la Unidad Gerencial de Desarrollo Integral de la familia y Promoción del Voluntariado (UGD1FPV), entre otros; y adscribió la Unidad Gerencial de Investigación Tutelar (UGIT) a la secretaría nacional de adopciones.

\footnotetext{
1 En algunos casos se configura el abandono cuando los padres raras veces visitan a sus hijos y, finalmente, son prácticamente olvidados. Esta misma situación se presenta con relación a las madres solteras, que también carecen de recursos económicos y optan por internar a sus hijos en estos establecimientos de tutela, para finalmente no preocuparse más por ellos.
} 
En aplicación a la citada ley; se dispuso el retomo de la UGDIFPV y la UGIT al INABIF, según lo establecido en el manual de Organización y Funciones aprobado con Resolución Ministerial 452-2005-MINDES. En este proceso de reestructuración de competencias del MIMDES, a partir del mes de Julio de 2008, se reincorporaron en sus actividades la UGDIFPV y la UGIT al INABIF.

En tanto se realiza la investigación tutelar, la UGIT o el juzgado de familia puede disponer el intemamiento provisional del niño en un hogar del INABIF. Esta investigación involucra la búsqueda y ubicación de familiares, a fin de determinar si algún pariente del niño puede hacerse cargo del menor si es que éste no puede regresar con sus padres porque ellos no aseguran su adecuado desarrollo. ${ }^{2}$

Es en ésta etapa donde se le practica un examen médico legal y exámenes complementarios: reconocimiento de Edad Aproximada, Integridad Física, Integridad Sexual, exámenes de VIH y VDRL, examen Psicológico y Social para establecer el estado mental, emocional para así conocer la situación familiar del niño.

Estos exámenes deben haber sido practicados antes de que el niño ingrese al INABIF (su gestión corresponde a la PNP o Ministerio Público). Si por la urgencia del caso, no se hubieran realizado, el INABIF -previa autorización judicial- deber realizarlos en el más breve plazo. ${ }^{1}$

Una vez que un niño es puesto a disposición del INABIF, el equipo profesional de la Gerencia de Protección Integral lo evalúa y ubica en el hogar que le corresponde de acuerdo a su perfil personal. Ya en el hogar es recibido por el director y el Equipo Técnico, quienes se encargan de su cuidado hasta que se determine su situación legal.

Es importante señalar también que a partir de la aprobación de la Ley $\mathrm{N}^{\circ}$ 28330, que modifica diversos artículos del Código de los Niños y Adolescentes, respecto al proceso de investigación tutelar se otorga competencia para realizar el proceso de investigación tutelar al Ministerio de la Mujer y Desarrollo Social -MIMDES, en su calidad de Ente Rector en materia de Infancia y Adolescencia. Sin embargo, mientras esta competencia no sea asumida formalmente por el MIMDES, el Poder Judicial sigue resolviendo los problemas de este grupo social, ante la falta de políticas sociales de protección por parte del Estado.

En tal sentido, en concordancia con la Ley 27337 Ley que aprueba el nuevo Código de los niños y adolescentes en el Perú (07/08/00) y el reglamento de los capítulos IX y X del Título II del Libro cuarto del Código de los niños y adolescentes D.S. 0011 2005-MIMDES tenemos una legislación que nos estipula cuales son las diligencias y pasos a seguir en este procedimiento. Lo que se busca es que las instituciones que tienen a su cargo dichas diligencias trabajen de forma conjunta para poder mejorar la situación del proceso, la misma que va más allá de esta legislación.

2 Sobre el particular, es necesario notificar mediante el Diario El Peruano o diarios judiciales,

sobre la situación de abandono que se encuentra el niño. La notificación contiene los datos más importantes del menor, como los rasgos de niño y el lugar donde fue hallado.

La investigación realizada es profunda y detenida dirigida

específicamente a obtener referencias

de aproximación hacia los progenitores. 


\section{PROBLEMÁTICA.JURÍDICA CON REPERCUSIONES \\ PSICOLOGICAS}

Como puede verse existen diversas causas que originan la inadecuada aplicación de la ley del Código de los niños y adolescentes con respecto a la investigación tutelar.

Partiendo de problemas administrativos como la falta de personal capacitado y especializado en los juzgados respectivos, la carga no solo en dichos juzgados sino en el equipo multidisciplinario de nuestro poder judicial, conlleva a una comunicación poco fructífera entre los albergues y el juzgado así como la demora en cada diligencia que se debe llevar para avanzar cada uno de los casos.,

Dos podrían ser parte de las soluciones planteadas para tratar de aminorar los mencionados problemas, concentrándonos específicamente en la etapa del proceso de la investigación, antes de la declaración de abandono.

El trabajo en Red del Juzgado respectivo, el 1NABIF, RENIEC y el multidisciplinario, ya que actualmente existen procesos iniciados en el 2002 que aún en se encuentran sin la declaración de abandono, está demás decir que los resultados urgen ya que estamos hablando de casi 10 años de espera de un menor.

Una posible auditoria en el caso de los albergues de modo tal que se agilice, de identifique y se reorganice aquellos casos críticos para que no terminen en la lista de menores que por cumplir la mayoría de edad pasan de una espera de la declaración de abandono, a un archivo definitivo de su proceso, por ya no tener la edad correspondiente.

Sobre la base de lo anteriormente mencionado, cabe resaltar que los menores de edad declarados en abandono, son en su gran mayoría NN., con características muy difíciles pero con algún común denominador. ${ }^{4}$

Ahora bien, ¿Qué proceso se espera para menores con algunas "características especiales"? Mencionando algunos casos, tenemos:

- Hijos de progenitores con VIH

- Hijos de progenitores con retardo

mental

- Menores con alteraciones mentales

- Menores con esquizofrenia

- Retraso psicomotor

- Niños con labio leporino

Partiendo de cualquiera de éstos casos, la espera de la declaración de abandono repercute de manera preocupante en el perfil psicológico del menor, no solo hablamos de la real repercusión que un niño tiene al encontrarse en un estado de abandono, sino hablamos de una situación alarmante donde la revictimización se encuentra presente.

$4 \quad$ Sin dejar de lado los casos donde el menor es dejado en instituciones hospitalarias con el evi -

dente propósito de abandonarlos debido a la situación de enfermedad o al tratamiento costoso al que tendría que efectuarse. Ocurrido esto, el Ministerio Público debe constituirse en el lugar de los hechos, verificar la situación del menor, levantar el acta correspondiente y solicitar al juzgado especializado que inicie la respectiva investigación tutelar. 
La institución de la Adopción, que inicia con la declaración de abandono y el cual tiene de fondo la investigación tutelar, se traduce en un resultado esperado por nuestro sistema.

Ello resulta acorde a que se busca encontrar posteriormente una familia idónea para un niño y no un niño para una familia, como erróneamente se cree.

No estamos hablando de una declaración de abandono para que luego un menor sea ubicado en una familia con "amor para brindar", sino un adecuado análisis psicológico de una familia que tenga las características necesarias y reales que lleguen a comulgar con un menor que fue víctima del abandono, que inició con ciertos problemas y que corren un gran riesgo que sea su estado agravado a consecuencia de la demora de su investigación tutelar.

\section{V. CONCLUSIONES:}

La necesidad y la obligatoriedad de un debido proceso de declaración de estado de abandono, dependerá de la comunicación continua entre las instituciones (CAR), los juzgados especializados, Reniec y el Ministerio Público. Si dicha dinámica no se está realizando en los parámetros ya fijados por nuestra legislación, la repercusión legal desembocaría en repercusiones psicológicas que truncan el futuro del menor, ya que ningún tratamiento recuperaría las deficiencias del desarrollo volitivo si la espera es, como está ocurriendo actualmente, de más de nueve años, cuando el tiempo estimado es de solo meses para dicha investigación.

El planteamiento de un sistema de auditoría constante frente a la problemática de la organización en los CAR, contribuiría a evitar la revictimización de un menor, ya que se debe encontrar un ambiente adecuado conforme al perfil psicológico de determinada persona, de forma tal que un niño diagnosticado clínicamente sano, sea en un futuro dado en adopción sin sufrir las consecuencias de haber permanecido tantos años en un albergue no acorde al bienestar establecido, y al real interés superior del niño en pleno sentido de la palabra.

La tutela judicial efectiva solo puede alcanzar su real objetivo mediante un debido proceso que incluya todas las garantías y con un alto grado de perfeccionamiento en cada uno de los intervinientes. En el mismo sentido se necesita que los plazos viables sean inmediatos, así como también el promedio normal y viable de accesión procesal, la justificación procesal, la independencia del órgano jurisdiccional y un mínimo de procesos observados, dejando de laso toda tendencia simplista administrativa.

Las relaciones emocionales precarias de un menor establecidas durante un proceso de investigación tutelar, tienden a transformarse en las bases de repercusiones de la personalidad en la vida adulta (tratando de hacer énfasis en el peligro de una personalidad malsana), y si dicho de ésta forma le parece exagerado a cualquier lector, estamos dejando de lado la verdadera responsabilidad por parte de los operadores judiciales, jueces e instituciones, que necesitan tomar una real conciencia de que la posesión más importante del niño en el comienzo de su vida es la afectividad sana. Afectividad, que solicita un debido proceso y una cuantificación de las medidas de protección previstas en el código del niño y adolescente. 